\title{
Laboreal
}

Volume $10 \mathrm{~N}^{\circ} 1$ | 2014

Análise ergonómica do trabalho e formação

\section{A atividade dos formadores no reconhecimento e validação de adquiridos: a evolução de um instrumento a partir da atividade}

La actividad de los formadores en el reconocimiento y validación de

conocimientos adquiridos: la evolución de un instrumento a partir de la

actividad

L'activité des formateurs dans le cadre de la reconnaissance et la validation des acquis : l'évolution d'un instrument à partir de l'activité

The trainers' activity in the Recognition and Validation of Prior Learning: the development of an instrument from the activity

Joana Fernandes e Marta Santos

\section{OpenEdition}

Journals

\section{Edição electrónica}

URL: http://journals.openedition.org/laboreal/5278

DOI: $10.4000 /$ laboreal.5278

ISSN: 1646-5237

\section{Editora}

Universidade do Porto

\section{Refêrencia eletrónica}

Joana Fernandes e Marta Santos, «A atividade dos formadores no reconhecimento e validação de adquiridos: a evolução de um instrumento a partir da atividade », Laboreal [Online], Volume $10 \mathrm{~N}^{0} 1$ | 2014, posto online no dia 01 julho 2014, consultado o 09 outubro 2019. URL : http:// journals.openedition.org/laboreal/5278; DOI : 10.4000/laboreal.5278

Este documento foi criado de forma automática no dia 9 outubro 2019

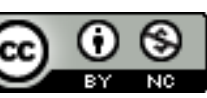

Laboreal está licenciado com uma Licença Creative Commons - Atribuição-NãoComercial 4.0 Internacional. 


\title{
A atividade dos formadores no reconhecimento e validação de adquiridos: a evolução de um instrumento a partir da atividade
}

\author{
La actividad de los formadores en el reconocimiento y validación de \\ conocimientos adquiridos: la evolución de un instrumento a partir de la \\ actividad \\ L'activité des formateurs dans le cadre de la reconnaissance et la validation des \\ acquis : l'évolution d'un instrument à partir de l'activité \\ The trainers' activity in the Recognition and Validation of Prior Learning: the \\ development of an instrument from the activity
}

Joana Fernandes e Marta Santos

\section{NOTA DO EDITOR}

http://dx.doi.org/10.15667/laborealx0114jf

Manuscrito recebido em: fevereiro/2014

Aceite após peritagem: maio/2014

1 Investigações anteriores que conduzimos sobre o sistema de reconhecimento e validação de adquiridos (RVA) português, centradas, entre outros aspetos, na análise da atividade dos formadores neste sistema (Caramelo \& Santos, 2013; Fernandes, 2014; Fernandes \& Santos, 2010; Fernandes \& Santos, 2012a; Fernandes \& Santos, 2012b; Santos \& Caramelo, 2013; Santos \& Fernandes, 2014) evidenciaram que a sua atividade se caracteriza, entre outros aspetos, pela ambivalência, obrigando cada formador a uma gestão complexa e, por vezes, solitária de um conjunto de desafios. Desde logo, o principal instrumento da atividade, o referencial de competências-chave (ANEFA, 2001), 
é considerado pelos formadores como sendo vago, difuso e confuso, conduzindo-os à reconcepção do referencial e também à conceção de novos instrumentos para o reconhecimento e a validação de competências. Independentemente das opções singulares que cada formador acaba por tomar para a gestão da sua atividade, o que parece ser consensual é a forma como os formadores percecionam a margem de manobra que lhes é concedida: ora como a autonomia de que necessitam para poderem ter em conta os percursos e experiências dos adultos (tão importante neste processo), ora como a necessidade de tomar decisões individualmente, sem o conhecimento das opções efetuadas pelos outros formadores e, portanto, na ausência de uma validação da sua atividade pelo coletivo de trabalho. Foram estes elementos que nos mostraram a importância de aumentar a compreensão sobre a atividade dos formadores neste processo e, em especial, em relação à evolução de um instrumento a partir da atividade. Esta análise foi sobretudo sustentada em contributos de Béguin e Rabardel, acerca da atividade mediada (Béguin, 2007a; Béguin, 2007b; Béguin, 2008; Béguin \& Rabardel, 2000; Rabardel, 1995, 1999; Rabardel \& Béguin, 2005).

\section{O Reconhecimento e a Validação de Adquiridos em Portugal}

\subsection{Dimensões de Intervenção e Atores}

2 Foi no final da década de noventa do século XX que, em Portugal, se começaram a dar os primeiros passos para o estabelecimento de um sistema de RVA, designado por sistema de Reconhecimento, Validação e Certificação de Competências (RVCC), sendo esta uma das atribuições da Agência Nacional de Educação e Formação de Adultos [ANEFA] (Decreto-Lei n. ${ }^{\circ}$ 387/99, de 28 de Setembro). Sob a responsabilidade da ANEFA foi concebido e editado o primeiro referencial de competências-chave português, o Referencial de Competências-Chave para a Educação e Formação de Adultos (ANEFA, 2001), que viria a ser utilizado para o desenvolvimento de processos de RVCC e de outras modalidades formativas. Assim, em Portugal e desde 2001, é possível aceder a uma certificação escolar de nível básico através do processo de RVCC. Estes processos começaram por ser desenvolvidos em Centros de Reconhecimento Validação e Certificação de Competências (CRVCC); em 2007 deram lugar aos Centros de Novas Oportunidades (CNO) e foram, em dezembro de 2013, substituídos pelos Centros para a Qualificação e Ensino Profissional (CQEP). Desde 2006, a certificação profissional e a certificação escolar de nível secundário pela via do RVCC, tornaram-se também possíveis.

3 O processo de RVCC foi estruturado em três eixos de intervenção: (i) o reconhecimento; (ii) a validação e (iii) a certificação. Na etapa de reconhecimento, o adulto [1], com o apoio do formador, identifica as competências adquiridas, ao longo da vida, em diferentes contextos (formais, não-formais e informais). 0 produto desta análise vai resultando na (re)construção de um portefólio reflexivo de aprendizagens (PRA) (Gomes \& Canelas, 2007). Em termos metodológicos o processo desenvolve-se através de abordagens autobiográficas, em que se inserem as histórias de vida, o PRA e o balanço de competências (Gomes, 2006). Quando são detetadas lacunas em termos de competências demonstradas pelos adultos face ao referencial do nível de certificação para que se candidatam, desenvolvem-se ações de formação complementar (no máximo 
de 50 horas por adulto), baseadas nas áreas de competências-chave dos respetivos referenciais (Gomes \& Canelas, 2007). A etapa seguinte, de validação das competências, centra-se na realização de uma sessão, na qual o adulto e a equipa técnico-pedagógica analisam e avaliam o PRA, face ao referencial de competências-chave identificando as competências a validar e a evidenciar/desenvolver. O terceiro eixo, da certificação, corresponde ao final do processo de RVCC, e consiste na confirmação oficial e formal das competências validadas através do processo, realizando-se através de uma apresentação oral a um júri de certificação. Se as competências validadas nesta fase forem consideradas suficientes, o adulto tem acesso a uma certificação total, caso não o sejam, através de uma certificação parcial, o adulto será encaminhado para um percurso formativo definido a partir da identificação das suas necessidades formativas.

4 A equipa que desenvolve o processo de reconhecimento e validação de adquiridos é composta por profissionais de reconhecimento, validação de competências (RVC) e formadores. Ambos são responsáveis pela prestação de apoio a cada adulto, orientando a construção do PRA e participam em todos os eixos de intervenção (reconhecimento, validação e certificação). A cada formador é pedido que apoie o adulto na área de competência-chave em que se insere. Por exemplo, ao formador de Matemática para a Vida, uma das áreas de competência-chave do referencial, é requerido que identifique e valide competências nessa mesma área. Enquanto o profissional de RVC introduz as abordagens autobiográficas, procurando tornar o adulto disponível para a reflexividade e a exploração da sua trajetória.

O profissional de RVC e os formadores devem possuir, preferencialmente, formação e experiência especializadas no domínio da educação e formação de adultos. Os formadores devem estar formalmente habilitados para o exercício da atividade de professor no ensino regular, conforme definido pelo Ministério da Educação, para poder atuar nestes processos. O profissional de RVC deve ser detentor de uma qualificação de nível superior. Esta equipa reporta à direção do centro.

\subsection{Instrumento para Reconhecer, Validar e Certificar Competências}

6 É no Referencial de Competências-Chave (ANEFA, 2001) que estão identificadas as competências que devem ser demonstradas para o acesso a uma certificação. Este referencial, para o nível básico, organiza-se em quatro áreas de competência-chave: (i) Linguagem e Comunicação (LC); (ii) Matemática para a Vida (MV); (iii) Tecnologias de Informação e Comunicação (TIC) e, (iv) Cidadania e Empregabilidade (CE). Cada área de competência-chave está estruturada em quatro unidades de competência - A, B, C e D, de acordo com três níveis de certificação - B1, B2 e B3, correspondentes aos ciclos do ensino básico: $1 . .^{\circ}$ ciclo, $2 .^{\circ}$ ciclo e $3 .^{\circ}$ ciclo [ $\left.{ }^{2}\right]$. Neste referencial, enquanto principal instrumento prescrito para o RVA, estão identificadas as competências que cada formador deve reconhecer e validar, para posteriormente decidir acerca da certificação.

7 O referencial, disponível em formato de papel e digital, é apresentado ao longo de 211 páginas e estrutura-se em duas partes. Num primeiro momento é feita uma descrição do desenho global do referencial e numa segunda parte privilegiada a abordagem específica a cada uma das áreas. Não é possível encontrar uma coerência relativamente aos campos que compõem a abordagem a cada uma das áreas do referencial, à exceção 
da "fundamentação" que inaugura a explicitação de todas as áreas e da identificação dos critérios de evidência relativos a cada área. Em nenhuma das áreas é explicitada a escala que os formadores devem utilizar para a apreciação das competências e para a decisão de validação.

\section{A Atualização no Uso}

\subsection{O Instrumento: no Encontro entre a Dimensão Artefactual e a Dimensão Humana}

8 A relação que se estabelece entre a pessoa e o objeto para o alcance de um determinado objetivo é mediada, através de signos e instrumentos [3]. Rabardel (1995) distinguiu três tipos de mediação instrumental. A mediação do objeto que se refere à ação do sujeito sobre o objeto, podendo assumir dois formatos: epistémica, quando orientada para a familiarização com o objeto e as suas propriedades e, pragmática, sempre que se centra na ação sobre o objeto, seja ao nível da sua transformação ou manipulação. Um ou outro tipo de mediação, epistémica ou pragmática, pode ser predominante mas habitualmente interagem ambas na ação. A mediação reflexiva ou heurística refere-se à relação que o sujeito estabelece consigo próprio através do instrumento. Finalmente, a mediação interpessoal é relativa às relações mediadas com outros. Este tipo de mediação também se enquadra nas mediações colaborativas, em contextos coletivos.

Portanto se a relação entre o sujeito e o objeto é mediada, uma análise do artefacto deve ser desenvolvida atendendo à forma como este é mobilizado na ação pelo sujeito.

O artefacto não é em si mesmo um instrumento, é o sujeito que lhe confere e atribui esse estatuto quando o inscreve numa ação específica e o mobiliza como meio de ação (Rabardel \& Béguin, 2005), desenvolvendo-o como um instrumento na sua atividade. $O$ instrumento é, por isso, uma entidade combinada (Béguin, 2007a, 2008; Rabardel \& Béguin, 2005) que tem origem, simultaneamente, no objeto e no sujeito (Daniellou, 2005), composta por:

- uma componente artefactual: dimensão que é envolvida na ação, relativa ao artefacto, para o alcance de um dado objetivo (Béguin, 2007b);

- uma componente humana: dimensão que tem origem no sujeito, que integra dimensões individuais, sociais e culturais relativas ao utilizador e ao sistema (Béguin, 2007b; Béguin, 2008; Daniellou, 2005). Esta componente humana relaciona-se com os esquemas de utilização, estruturas ativas que integram experiências anteriores, e que se constituem como referência para a interpretação de novos dados (Béguin, 2007a; Rabardel \& Béguin, 2005). Neste sentido, o envolvimento de um instrumento na ação, enquanto "componente funcional da ação individual" (Rabardel \& Béguin, 2005, p.442, tradução livre), implica, simultaneamente, a mobilização da sua dimensão humana e artefactual.

11 O processo de apropriação da novidade técnica e de conceção na utilização pelos utilizadores designa-se génese instrumental. Como referido anteriormente, o instrumento é uma entidade bipolar, portanto a génese instrumental envolve tanto a dimensão humana (pela instrumentação), como a dimensão artefactual (através da instrumentalização) (Béguin, 2007a; Béguin, 2007b; Béguin, 2008). 


\section{Método}

Decorrente do enquadramento teórico anterior, esta pesquisa procurou conhecer as funções que o referencial de competências-chave (ANEFA, 2001) desempenha na atividade do formador no RVA e compreender como este referencial evolui a partir da atividade dos formadores.

\subsection{Participantes}

No contexto de entrevista coletiva (em pares), participaram nesta pesquisa dez formadores (Ver Quadro 1).

Quadro 1: Caracterização dos Formadores que Participaram nas Entrevistas Coletivas

\begin{tabular}{|c|c|c|c|c|c|c|c|c|}
\hline Código & $\begin{array}{l}\text { Data } \\
\text { Entrevista }\end{array}$ & Duração & Género & Idade* & $\begin{array}{l}\text { Habilitações } \\
\text { Escolares* }\end{array}$ & $\begin{array}{l}\text { Área de } \\
\text { Formação }\end{array}$ & $\begin{array}{l}\text { Antiguidade } \\
\text { na Função } \\
\text { (em anos)* }\end{array}$ & $\begin{array}{l}\text { Tipologia } \\
\text { CNO }\end{array}$ \\
\hline EC1 & \multirow{2}{*}{ Abril 2011} & \multirow{2}{*}{$01 \mathrm{~h} 54 \mathrm{~m}$} & $F$ & 32 & Licenciada & $\begin{array}{l}\text { Engenharia } \\
\text { Informática }\end{array}$ & 5 & $\begin{array}{l}\text { IEFP e } \\
\text { Privado }\end{array}$ \\
\hline EC2 & & & $F$ & 39 & Licenciada & $\begin{array}{l}\text { Química } \\
\text { Analítica }\end{array}$ & 4 & Privado \\
\hline EC3 & \multirow[t]{2}{*}{ Abril 2011} & \multirow[t]{2}{*}{$02 \mathrm{~h} 16 \mathrm{~m}$} & $F$ & 35 & Licenciada & $\begin{array}{l}\text { Matemáticas } \\
\text { Aplicadas - } \\
\text { Ramo } \\
\text { Educacional }\end{array}$ & 4 & Privado \\
\hline EC4 & & & $F$ & 29 & Licenciada & $\begin{array}{l}\text { Engenharia } \\
\text { Biológica }\end{array}$ & 2 & Privado \\
\hline EC5 & \multirow[t]{2}{*}{$\begin{array}{l}\text { Junho } \\
2011\end{array}$} & $02 \mathrm{~h} 01 \mathrm{~m}$ & $F$ & 34 & Licenciada & $\begin{array}{l}\text { Matemáticas } \\
\text { Aplicadas - } \\
\text { Ramo } \\
\text { Educacional }\end{array}$ & 4 & Privado \\
\hline EC6 & & & $F$ & 30 & Licenciada & $\begin{array}{l}\text { Engenharia } \\
\text { Química }\end{array}$ & 4 & $\begin{array}{l}\text { IEFP e } \\
\text { Privado }\end{array}$ \\
\hline EC7 & \multirow[t]{2}{*}{$\begin{array}{l}\text { Junho } \\
2011\end{array}$} & \multirow[t]{2}{*}{$01 \mathrm{~h} 47 \mathrm{~m}$} & $F$ & 28 & Licenciada & $\begin{array}{l}\text { Matemáticas } \\
\text { Aplicadas - } \\
\text { Ramo } \\
\text { Educacional }\end{array}$ & 3 & IEFP \\
\hline EC8 & & & M & 46 & Licenciado & $\begin{array}{l}\text { Engenharia } \\
\text { Química }\end{array}$ & 1 & IEFP \\
\hline
\end{tabular}




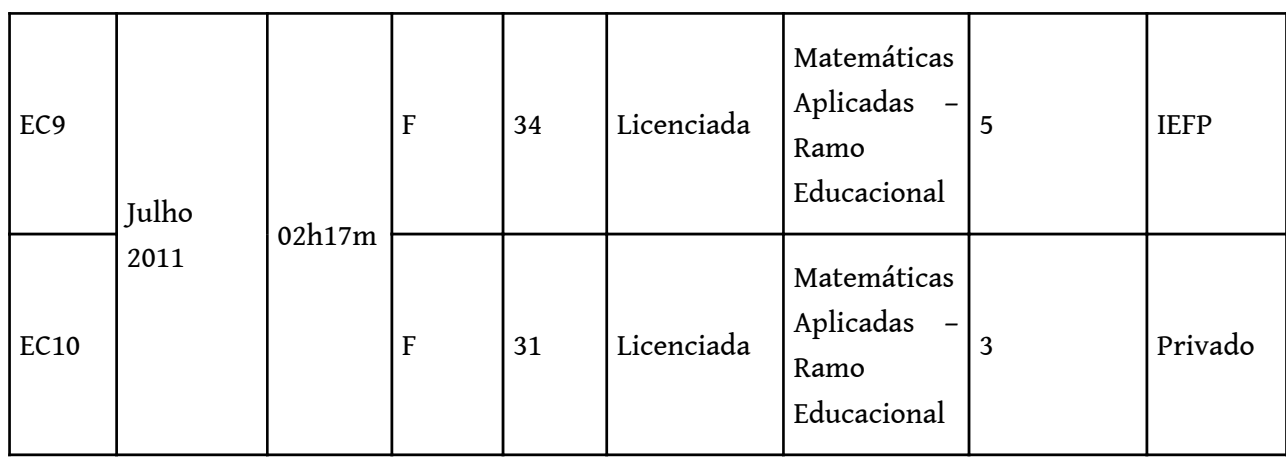

$\mathrm{O}$ total de formadores (um homem e nove mulheres, Mage $=33.8, \mathrm{SD}=5.4$, intervalo etário: 28-46 anos) tinha uma antiguidade de trabalho no processo de RVCC que variava entre um e cinco anos $(\mathrm{M}=3.6 ; \mathrm{SD}=1.2)$. Relativamente à área de formação, cinco formadores são licenciados na área da Matemática (ensino de Matemática) e os restantes em Engenharia (Química e Biológica). No que se refere à tipologia da entidade promotora: um dos formadores trabalhava num centro com ligação ao Instituto de Emprego e Formação Profissional (IEFP); um outro formador trabalhava, em simultâneo, em dois centros de diferentes tipologias (IEFP e privado); e os restantes oito desenvolviam a sua atividade numa entidade privada. Todos os formadores com formação ao nível da Matemática têm experiência profissional, anterior e/ou atual, no ensino regular.

Participaram, ainda, nesta pesquisa três formadores e uma profissional de RVC através do acompanhamento desenvolvido, em contexto real, de um processo de RVCC decorrido numa empresa do setor metalúrgico, situada no Norte de Portugal, especializada na área da serralharia civil, nas vertentes de alumínio, ferro e inox. Alguns dados de caracterização destes trabalhadores encontram-se disponíveis no Quadro 2.

Quadro 2: Caracterização da Equipa Técnico-Pedagógica Responsável pelo Grupo de Formação do Setor Metalúrgico

\begin{tabular}{|l|l|l|l|l|l|l|}
\hline Código & Género & Idade* & $\begin{array}{l}\text { Habilitações } \\
\text { escolares* }\end{array}$ & Área de formação & $\begin{array}{l}\text { Habilitação } \\
\text { própria para } \\
\text { docência* }\end{array}$ & Função \\
\hline T1 & F & 25 & Licenciatura & Psicologia & Não & $\begin{array}{l}\text { Profissional } \\
\text { RVC }\end{array}$ \\
\hline T2 & M & 41 & Licenciatura & Matemáticas Aplicadas & Sim & Formador \\
\hline F & 30 & Licenciatura & $\begin{array}{l}\text { Matemáticas Aplicadas - } \\
\text { Ramo Educacional }\end{array}$ & Sim & Formador \\
\hline T4 & F & 30 & Licenciatura & $\begin{array}{l}\text { Modernas - Variante de } \\
\text { Estudos Portugueses e } \\
\text { Franceses }\end{array}$ & Sim & Formador \\
\hline
\end{tabular}


16 A equipa era constituída por três formadores, que asseguraram as quatro áreas do referencial (LC, CE, TIV e MV) e pela profissional de RVC. Estes quatro elementos da equipa tinham idades compreendidas entre os 25 e os 41 anos $(M=31,5 ; S D=6,8)$. Dos quatro elementos que compunham a equipa, três são do género feminino. Todos os trabalhadores são licenciados e apenas T1, profissional de RVC, não possui habilitação própria para a docência.

\subsection{Instrumentos}

17 A entrevista coletiva e a análise da atividade foram os instrumentos privilegiados para o acesso e a recolha dos dados. Procurou-se desenvolver conhecimento a partir da perspetiva dos formadores, partindo-se da análise de diversos elementos constitutivos da atividade: o que era esperado que fizessem (ao nível do prescrito); aquilo que efetivamente faziam e como faziam; aquilo que não faziam (porque não podiam ou não conseguiam); e também aquilo que faziam, por ser o possível num dado momento.

Privilegiaram-se, então, os métodos de acesso e de construção de conhecimento que associam os protagonistas da situação de trabalho à sua análise (Clot, Faïta, Fernandes, \& Scheller, 2000), complementada com a análise em contexto.

\subsection{Procedimento de recolha e análise dos dados}

O acompanhamento do processo em contexto real desenvolveu-se entre março e dezembro de 2010, e consistiu na participação, pela observação, em todas as sessões de reconhecimento e formação complementar da área de MV, num total de 29 horas. Durante estas sessões foram registadas as verbalizações dos adultos e da formadora de $\mathrm{MV}$, e foram arquivados todos os instrumentos e atividades desenvolvidos no âmbito do processo.

20 As entrevistas coletivas decorreram entre abril e julho de 2011. Estas foram gravadas em formato áudio e vídeo, para posterior análise e transcrição. Estes dados foram arquivados, organizados e analisados pelo recurso ao software Nvivo9.

\section{Análise e Discussão dos Dados}

\subsection{A Utilização do Referencial}

21 Como referido anteriormente, o referencial de competências-chave é o principal instrumento prescrito para reconhecer e validar competências. Procurou-se compreender de que forma este referencial estruturava concretamente a atividade dos formadores, no objetivo de reconhecer e validar competências. A partir da análise em contexto foi possível identificar os momentos em que o referencial era utilizado e qual o significado e objetivo da sua utilização em cada momento.

o Quadro 3 identifica os momentos em que o referencial foi utilizado no eixo de reconhecimento do processo de RVCC acompanhado na empresa do setor metalúrgico. 
Quadro 3: Momentos e Significados da Utilização do Referencial no Eixo do Reconhecimento

\begin{tabular}{|c|c|c|c|c|c|c|c|c|}
\hline N.․ Sessão & \begin{tabular}{l|l}
1 & 2
\end{tabular} & 3 & \begin{tabular}{l|l}
5 & 6
\end{tabular} & 7 & 8 & 10 & 11 & 12 \\
\hline $\begin{array}{l}\text { Significado da } \\
\text { utilização } \\
\text { Referencial }\end{array}$ & $-1-$ & $\begin{array}{l}\text { Levantamento de } \\
\text { competências nas } 4 \\
\text { áreas de } \\
\text { competência-chave }\end{array}$ & Descodificação & - & Diagnósti & tico & - & - \\
\hline Responsável & \multicolumn{2}{|c|}{ Profissional RVC } & Formador & $\begin{array}{l}\text { Profissional } \\
\text { RVC }\end{array}$ & \multicolumn{2}{|l|}{ Formador } & \multicolumn{2}{|c|}{$\begin{array}{l}\text { Profissional } \\
\text { RVC }\end{array}$} \\
\hline
\end{tabular}

As três primeiras sessões foram desenvolvidas pela profissional de RVC (T1) e tiveram como objetivos: a apresentação dos participantes; a distribuição do cronograma; o fornecimento de informação sobre o funcionamento do processo; e, a identificação de expectativas em relação ao processo. Nestas duas sessões iniciais o referencial, no formato original ou adaptado, não foi ainda mobilizado.

$\mathrm{Na}$ fase final da terceira sessão foi distribuída uma atividade intitulada - Levantamento de competências nas quatro áreas de competência-chave, na qual foi solicitado a cada formando que identificasse e registasse, num formato de resposta "sim" ou "não", se possuía cada uma das competências existentes numa lista e referisse a situação de vida em que a desenvolveu [4]. O objetivo desta atividade pareceu relacionar-se com a tentativa de aproximação dos formandos às áreas de competência-chave, procurando também facilitar o posterior reconhecimento de competências por parte dos formadores. Neste caso, e pelo facto de a atividade ter sido completada pela maior parte dos formandos apenas numa fase final do processo, a mesma não cumpriu esse fim.

Tal como o Quadro 3 procurou ilustrar, as sessões seguintes, n.4, n. .5 e n.ำ foram dedicadas áquilo que os formadores habitualmente designaram de descodificação do referencial. $\mathrm{Na}$ área de MV essa descodificação foi desenvolvida pela resolução de quatro fichas que simultaneamente permitiram "traduzir" o referencial e identificar as competências que cada participante possuía.

No concreto, nas sessões de MV, a tradução do referencial foi feita através da resolução de fichas com exercícios de tipo escolar. Era através da sua resolução que a formadora (T3) conseguia, simultaneamente, apresentar o referencial e avaliar as competências e os saberes de que os adultos eram detentores. Depois de uma nova sessão com a profissional de RVC, sessão $n .{ }^{\circ}$ 7, para monitorização do desenvolvimento do processo, os formadores dedicaram-se, nas sessões n.ํ, n. .9 e n. .10 , ao diagnóstico de competências, para determinação das competências já adquiridas e das que estavam em falta. $O$ eixo do reconhecimento terminou após duas novas sessões, sessões n. ${ }^{\circ} 11$ e n.ำ12 com a profissional de RVC, em que procurou que os formandos fizessem um balanço do processo e definissem planos para o futuro.

Após a conclusão da etapa do reconhecimento, os formadores analisaram os dossiers de cada candidato e reuniram para validação, definindo, neste momento, quais as competências já explicitadas e as que deveriam ser aperfeiçoadas ou adquiridas através de formação complementar.

Em síntese, apesar do referencial ser um instrumento central na estruturação da atividade dos formadores, ele vai evoluindo e cumpre finalidades muito distintas na 
atividade dos formadores, com destaque como vimos neste subcapítulo, para a descodificação e diagnóstico de competências.

\subsection{As Funções do Referencial}

O referencial em análise é uma entidade mediadora entre o formador e o objeto da sua ação. Procuraremos, de seguida, analisar as funções do referencial à luz dos tipos de mediação entre o sujeito e o objeto propostas por Rabardel (1995).

Os formadores entrevistados referiram-se ao referencial de diferentes formas mas salientam as funções de:

- reconhecimento das competências: quando se constitui enquanto recurso para a ação e permite ao formador agir no sentido da identificação das competências dos adultos. Esta formulação sobre o referencial pelos formadores parece querer dizer, que o instrumento pode assumir uma forma de uma mediação pragmática (Rabardel, 1995);

- orientação / guia da sua própria atividade, já que o referencial auxilia no conhecimento que os formadores passam a ter dos adquiridos pelos adultos que optam por estes processos, quando é a referência para o conhecimento do objeto (de acordo com Rabardel (1995), o instrumento assume, nestes casos, uma mediação epistémica);

- constrangimento, quando delimita aquilo que o formador pode valorizar no percurso dos adultos. Neste sentido, a utilização do referencial age sobre o próprio sujeito/formador, pelo que o tipo de mediação que de acordo com Rabardel (1995) está aqui em causa é uma mediação heurística ou reflexiva.

Os referenciais são, portanto, inegáveis instrumentos da atividade dos formadores, cumprindo diferentes funções que ora facilitam a consecução da finalidade da sua ação ora a constrangem e delimitam.

\subsection{A Zona de Valor Funcional do Referencial}

Rabardel (1999) reconheceu que a todo o artefacto se associa uma zona de valor funcional partilhada e situada, que constitui o sentido do artefacto, recuperando a analogia com a linguagem [5]. Parece, assim, ser possível estabelecer uma ligação entre esta zona de valor funcional partilhado do referencial e o conteúdo das entrevistas aos formadores, sobretudo ao nível da sua utilidade.

O Quadro 4 sinaliza o conjunto de categorias emergentes acerca da utilidade do referencial

Quadro 4: Identificação da Utilidade do Referencial.

\begin{tabular}{|l|l|l|}
\hline Designação & $\begin{array}{l}\text { Número de } \\
\text { Referências }\end{array}$ & Distribuição percentual \\
\hline Constranger a atividade & 3 & 5,9 \\
\hline Dar segurança ao formador & 4 & 7,8 \\
\hline Legitimar pedidos dos formadores & 3 & 5,9 \\
\hline
\end{tabular}




\begin{tabular}{|l|l|l|}
\hline Orientar a Atividade & $\mathbf{2 4}$ & $\mathbf{4 7 , 1}$ \\
\hline Ponto de partida & 4 & 7,8 \\
\hline Uniformizar, selecionar e sintetizar informação & 13 & 25,5 \\
\hline
\end{tabular}

Nota: valor mais elevado encontra-se a bold. Identificou-se, assim, que o referencial se
atividade dos formadores no processo de RVCC:

(...) eu acho importante existir um referencial e eu, como não venho do ensino, se eu não tivesse o referencial estava frita, porque não sabia o que havia de fazer. (EC4)

Esta utilidade ao nível da orientação da atividade parece relacionar-se com uma outra categoria, em que a existência de um referencial surge associada a uma perspetiva de segurança, por parte dos formadores,

Mas, no meu caso concreto, quando fui para um centro de reconhecimento de competências eu nem sequer sabia o que é que queria dizer a sigla RVCC, não é? Saía de lá, todos os dias, em pânico a dizer "eu amanhã não venho" porque eram RCC para um lado (...) para outro, e isto, e eu não percebia nada do que eles estavam para lá a dizer e, portanto, eu acho que para quem inicia atividade profissional neste tipo de processos ele [referencial] é importante, independentemente dos defeitos que possa ter. (EC3)

ao mesmo tempo que legitima o pedido que os formadores dirigem aos adultos em processo:

(...) não estamos a pedir as coisas porque nos apetece. (EC3)

(...) são esses critérios que terão que ser validados. (EC2)

E uniformiza e sintetiza a informação:

Aliás passa-se o mesmo no processo normal escolar. Portanto tem que haver sempre um programa, tem que haver para uniformizarmos, porque se não eu fazia uma coisa a colega fazia outra e andávamos aqui todos, quer dizer (...) (EC3)

No entanto, este referencial serve essencialmente enquanto ponto de partida, pois apesar de desempenhar um papel incontornável na estruturação da ação dos formadores, essa utilidade concretiza-se, essencialmente, através da sua contínua reconceção.

o referencial, enquanto instrumento da atividade, revelou-se também um constrangimento porque define e limita as competências que o formador pode considerar. 


\subsection{Descrição da Evolução do Referencial a partir da Atividade - Géneses Instrumentais}

\section{da atividade.}

Figura 1: Evolução da Utilização do Referencial de Competências-Chave. experiência. trabalho de análise e apropriação resultou a conceção de novos instrumentos, mais simples, para o desenvolvimento do processo. De entre estes novos instrumentos destacaram-se: a construção de grelhas próprias para a validação (cujo processo será explorado no próximo subcapítulo); a preparação de atividades para a explicitação, a identificação e a avaliação de competências; e, a construção de apresentações em que o formador tenta traduzir a linguagem científica do referencial em situações do quotidiano.

Neste sentido, a reconceptualização do referencial, independentemente do formato que assuma, pareceu cumprir dois objetivos: (i) traduzir os conceitos científicos do referencial numa linguagem mais simples e mais próxima do quotidiano dos participantes e (ii) tornar mais objetiva a atividade desenvolvida pelo formador neste processo. A necessidade da conceção de novos instrumentos surgiu, então, pela necessidade de diminuir (e controlar) a subjetividade do processo e o seu caráter vago provocado pela ausência de orientação no desenvolvimento da atividade. Talvez seja por este motivo que os formadores revelaram ambivalência em relação à autonomia que têm na organização e gestão do seu trabalho.

O desvio em relação à utilização prescrita do referencial é reveladora, por um lado, que o referencial no seu formato original não é capaz de auxiliar o formador na resposta bem-sucedida às necessidades da situação e, por outro, que o formador é capaz de o alterar e envolver na atividade para a inevitável atualização no uso (Rabardel, 1995).

\subsection{A Definição de Grelhas Próprias para a Validação}

A construção de grelhas próprias para a validação emergiu como uma etapa transversal

Compreendeu-se, pelos dados anteriores, que o referencial é um guia orientador para a identificação de competências e que a utilização deste instrumento evolui com a

Figura t: Evoluçao da Utillzaçao do Referencial de Competências-Chove. à evolução do referencial, consistindo na versão pessoal de cada formador para a decisão acerca da validação. Esta reconceptualização do referencial foi considerada 
pelos formadores como essencial para o desenvolvimento da sua atividade, pois consideram o referencial, no seu formato original, ininteligível.

As grelhas, que são sínteses pessoais daquilo que os formadores consideram ser as áreas principais dos referenciais e sobre as quais decidem acerca da validação, são também bastante distintas (Santos \& Fernandes, 2014). A análise do Quadro 5 revela que o número de competências exigido por cada formador para validação é distinto.

Quadro 5: Percentagem de Critérios de Evidência Mínimos para Validação [ $\left.{ }^{6}\right]$.

\begin{tabular}{|l|l|l|l|l|}
\hline Formadores MV & MVA & MVB & MVC & MVD \\
\hline EC1 & 75 & 63 & 38 & 33 \\
\hline EC2 & 75 & 75 & 54 & 33 \\
\hline EC3 & 63 & 50 & 38 & 67 \\
\hline EC4 & 75 & 50 & 46 & 67 \\
\hline EC5 & 75 & 50 & 62 & 33 \\
\hline EC6 & 75 & 50 & 54 & 50 \\
\hline EC7 & 63 & 75 & 38 & 33 \\
\hline EC8 & 38 & 38 & 8 & 0 \\
\hline EC9 & 100 & 75 & 32 & 50 \\
\hline EC10 & 88 & 75 & 54 & 83 \\
\hline
\end{tabular}

A análise do Quadro 5 revela, por exemplo, que a formadora EC8 não solicita a explicitação de qualquer critério de evidência da unidade D (MVD). Compreendeu-se, em contexto de entrevista, que esta formadora considerou esses critérios excessivamente complexos para integração no processo. Registaram-se, ainda, exemplos também contrastantes na unidade A (MVA), em que EC9 exige a explicitação de todos os critérios, enquanto EC8 requere apenas $38 \%$ da totalidade dos critérios desta unidade.

Em contexto de entrevista procurou-se compreender quais os elementos em que cada formador se baseava para determinar quais os critérios a serem considerados como obrigatórios. Decorrente da análise do conteúdo das entrevistas coletivas, foram identificadas seis categorias, aqui representadas no Quadro 6.

Quadro 6: Critérios para a Identificação dos Critérios Mínimos para Validação.

\begin{tabular}{|l|l|l|}
\hline Designação & $\begin{array}{l}\text { Número de } \\
\text { Referências }\end{array}$ & Distribuição percentual \\
\hline Bom senso & 2 & 9,1 \\
\hline
\end{tabular}




\begin{tabular}{|l|l|l|}
\hline Experiência de outros colegas & $\mathbf{1 0}$ & $\mathbf{4 5 , 5}$ \\
\hline Facilidade e frequência & 6 & 27,3 \\
\hline Formação ANQ & 1 & 4,5 \\
\hline Importância & 2 & 9,1 \\
\hline Utilidade prática & 1 & 4,5 \\
\hline
\end{tabular}

Nota: o valor mais elevado encontra-se a bold.

A consideração da experiência de outros colegas tornou-se bastante expressiva na tomada de decisão sobre os critérios mínimos. A partilha de experiência interpares registou-se tanto pelo contacto com colegas, sobretudo os mais experientes, do próprio centro, como também de outros centros.

E portanto em conversa com colegas vamos tentando. Inicialmente, no início do processo eu tinha muitas dúvidas se estava a fazer bem, se realmente chegava se não chegava e então tínhamos muita necessidade e mesmo assim vou tendo quando conheço pessoas de outros CNO de ir vendo como é que eles trabalham, o que é que validam, como é que validam experiências portanto estou confortável com aquilo que foi decidido. (EC5)

A facilidade dos critérios, a que se associa a sua frequência foi também ponderada pelos formadores na seleção dos critérios a serem considerados mínimos:

(...) estas mínimas são aquelas mais fáceis de operacionalizar, ou seja, é mais fácil dizer a uma pessoa tem que explicar um gráfico, do que dizer "olhe tem que em contexto de vida reconhecer funções como critério...”. "Desculpe isso é fazer o quê?" é complicado certo? (EC8)

51 Apesar de cada formador construir as suas grelhas pessoais tendo por base os critérios anteriormente identificados, em que se registou uma elevada variabilidade interformador, isto é, encontraram-se marcadas diferenças nos critérios solicitados pelos diferentes formadores, assistiu-se, por outro lado, através da análise da atividade, a uma utilização invariável destas grelhas junto de diferentes adultos. Assim, independentemente da trajetória individual, o formador avaliou os diferentes adultos em processo sobre a mesma grelha e os mesmos critérios. A partir das entrevistas também foi possível perceber que os critérios mínimos definidos por cada formador foram evoluindo ao longo do tempo em função da experiência que adquiriram, pelo confronto com diversos percursos e experiências dos adultos.

\section{Reflexões Finais}

Olhando por detrás da fachada

Procurou-se, neste trabalho, não só aumentar a compreensão sobre a atividade dos formadores neste processo, mas também aceder às condições em que o fazem. Nas raízes históricas do processo de RVCC em Portugal, encontra-se a opção por este processo justificada no facto de a nossa população estar subcertificada, valendo em 
termos de saberes e competências mais do que aquilo que as suas qualificações o demonstravam (Caramelo \& Santos, 2013; Santos \& Caramelo, 2013; Santos \& Fernandes, 2014). Porém, quando este processo foi gizado, no final do século XX, destinava-se apenas a alguns, às pessoas que eram detentoras de competências diversas e consolidadas, sendo assim compatível, pela quantidade de pessoas e pelo seu perfil, o recurso a metodologias autobiográficas. Na verdade, os especialistas que participaram na conceção do sistema de RVCC consideravam que esta resposta não deveria ser sequer maioritária, ponderando que apenas 10 a $15 \%$ da população adulta portuguesa pudesse integrar este sistema, uma vez que a maioria deveria beneficiar de formação de base e mais prolongada (Fernandes, 2014). Contudo, em poucos anos as práticas de RVA constituíram-se como a grande aposta governamental para o acesso à certificação escolar. Para além do crescimento exponencial de centros que passaram a ser necessários para o desenvolvimento deste processo, os programas de financiamento impuseram metas de certificação (que garantiam a subsistência dos centros e, por consequência, a manutenção dos postos de trabalho das equipas envolvidas), o que contribuiu para a difícil compatibilização com as práticas autobiográficas, o apoio personalizado e o tempo que estes processos exigem (Caramelo \& Santos, 2013; Santos \& Caramelo, 2013; Santos \& Fernandes, 2014). É, assim, no quadro destas condições e condicionantes que se revela e fundamenta a necessidade de os formadores desenvolverem e recriarem continuamente a sua própria atividade. mas também se recria a si próprio. Neste sentido, o formador não é um agente passivo que cria condições para a transformação de outros, mas antes um sujeito, também em transformação. Os diferentes métodos utilizados para o desenvolvimento de investigações em torno da atividade do formador no reconhecimento e validação de adquiridos (Fernandes \& Santos, 2010; Fernandes \& Santos, 2012a; Fernandes \& Santos, 2012b; Santos \& Fernandes, 2014), em especial, a análise da atividade e as entrevistas coletivas, têm de alguma forma criado condições para que o formador reconheça o seu contributo ativo neste processo.

No encontro com os formadores, e quando convidados a pensar a sua atividade, vão tomando consciência dos determinantes da sua atividade e das condições em que a desenvolvem. Criaram-se neste encontro condições, por exemplo, para a tomada de consciência em relação à pressão a que estão sujeitos (temos metas a cumprir e o facto de termos metas a cumprir faz com que nós, muitas das vezes, tenhamos de aceitar 
pessoas em processo de RVC que não têm de todo perfil para esse processo - EC3); a aceitação de que fazem o possível, determinado por uma série de constrangimentos (... uma coisa é o que as coisas são e outra coisa é o que as coisas deveriam ser, o ideal não é? - EC8) e que o fazem para o alcance de um resultado (E portanto temos que uniformizar, colocar o processo uniformizado não é, como eu estava a dizer, o ideal porque chega-se a um ponto e nós olhamos para um dossier e está tudo lá, está lá a tabela, está lá o gráfico, está lá a percentagem, não é? Quer dizer por um lado não é bom, não vamos dizer que é bom, o que é certo é que funciona desta forma e eles evidenciam as competências - EC6). Assim, a tomada de consciência por parte dos formadores em relação a aspetos determinantes da sua atividade, parece reunir elementos potenciais de intervenção, ainda que sob determinadas condições.

\section{BIBLIOGRAFIA}

Agência Nacional de Educação e Formação de Adultos (2001). Referencial de competências-chave de educação e formação de adultos (nível básico). Lisboa: Author.

Béguin, P. (2007a). In search of a unit of analysis for designing instruments. Artifact, 1(1), 12-16. http://dx.doi.org/10.1080/17493460600610830

Béguin, P. (2007b). Taking activity into account during the design process. Activités, 4(2), 115-121. http://activites.org/v4n2/beguin-EN.pdf

Béguin, P. (2008). Argumentos para uma abordagem dialógica da inovação. Laboreal, 4(2), 82-82. http://laboreal.up.pt/revista/artigo.php?id=37t45nSU547112341787:352:81

Béguin, P., \& Rabardel P. (2000). Mediating instruments: a developmental and anthropocentric point of view. Scandinavian Journal of Information Systems, 12, 173-200.

Caramelo, J., \& Santos, M. (2013). Vers une reconnaissance des acquis de l'expérience au Portugal. Formation Emploi, 122, 115-137.

Clot, Y. (2006). A função psicológica do trabalho. (A. Sobral, trad.). Petrópolis : Vozes.

Clot, Y., Faïta, D., Fernandez, G., \& Scheller, L. (2000). Entretiens en autoconfrontation croisée : une méthode en clinique de l'activité. Pistes, 2(1), 1-7.

Daniellou, F. (2005). The French-speaking ergonomists' approach to work activity: crossinfluences of field intervention and conceptual models. Theoretical Issues in Ergonomics Sciences, 6(5/6), 409-427.

Fernandes, J. (2014). Entre a Conceção e a Utilização de Instrumentos de Formação: a Análise da Atividade dos Formadores na Construção de uma Zona Funcional de Ação (Tese de Doutoramento não Publicada). Faculdade de Psicologia e Ciências da Educação da Universidade do Porto, Porto.

Fernandes, J., \& Santos, M. (2010, September). Training Trajectories and the Development of the Process of Recognition and Validation of Acquired Knowledge. Paper presented at the 6th European Research Conference, Adult Learning in Europe - Understanding Diverse Meanings and Contexts of European Society for Research on the Education of Adults, Sweden. 
Fernandes, J., \& Santos, M. (2012a). Instruments of trainers' activity: the use of referentials in processes of recognition and validation of prior learning. Work, 41, 4577-4583. doi: 10.3233/ WOR-2012-0754-4577

Fernandes, J., \& Santos, M. (2012b). Recognition and Validation of Competences: Process and Practices. Journal of Educational Sciences, 14(2), 9-18.

Gomes. M. (Ed.). (2006). Referencial de competências-chave para a educação e formação de adultos - nível secundário: guia de operacionalização. Lisboa: Direcção-Geral de Formação Vocacional

Gomes, M., \& Canelas, A. (2007). Carta de Qualidade dos Centros Novas Oportunidades. Lisboa: Agência Nacional para a Qualificação.

Rabardel, P. (1995). Les hommes et les Technologies: approache cognirive des instruments contemporains. Paris : Armand Colin.

Rabardel, P. (1999). Le langage comme instrument ? Éléments pour une théorie instrumentale étendue. In Y. Clot. (Eds.), Avec Vygotski (pp. 241-265). Paris : La Dispute.

Rabardel, P., \& Béguin, P. (2005). Instrument mediated activity: from subject development to anthropocentric design. Theoretical Issues in Ergonomics Sciences, 6(5/6), 429-461.

Santos, M., \& Caramelo, J. (2013). Le travail des formateurs au Portugal: entre l'analyse de l'activité et les politiques qui modèlent cette activité. In Société d'Ergonomie de Langue Française, Actes de le 48ème congrès international de la SELF.

Santos, M., \& Fernandes, J. (2014). La validation des acquis et leur reconnaissance par diplôme scolaire au Portugal: les référentiels de «compétences-clés» sont-ils une solution ou un problème? In B. Prot (Éd.). Les référentiels contre l'activité - En formation, gestion, certification. Toulouse : Octares.

Vygotsky, L. (1993). Teoria e método em Psicologia. (1ª edição) (C. Berliner, trad.). São Paulo: Martins Fontes.

Vygotsky, L. (1998). A formação social da mente. (6ª edição) (J. Neto, L. Barreto, \& S. Afeche, trad.). São Paulo: Martins Fontes.

\section{NOTAS}

1. No processo de RVCC, possivelmente pela vontade de afastamento de conceções mais escolarizadas e por se tratar de uma tipologia formativa ímpar, por se centrar nos adquiridos, os formandos em processo são habitualmente designados por adultos ou aprendentes.

2. Atualmente, em Portugal, a escolaridade mínima obrigatória é de 12 anos. 0 nível básico está organizado em três ciclos. O primeiro ciclo é composto por quatro anos, o segundo ciclo por dois anos e o terceiro ciclo por três anos de escolaridade. Após o ensino básico, de nove anos, inicia-se o ensino secundário, que se organiza em três anos.

3. O signo, ao mediar a reação individual face a um objeto ou tarefa, é um recurso da atividade interna de atuação do indivíduo sobre si próprio (Vygostki, 1993, 1998). Por sua vez, o instrumento dirige a influência humana sobre o próprio objeto (Vygostki, 1993, 1998).

4. Exemplo de um item apresentado nesta lista: Faço a gestão de orçamentos (familiar, associações, obras, sectores de empresas, pequenas empresas). 
5. Os artefactos, tal como as palavras, integram uma zona de estabilidade, de significado, que no caso do referencial remete para a função para o qual foi originalmente concebido, o reconhecimento e a validação de competências.

6. Para a identificação dos critérios mínimos foi apresentado, no final da entrevista coletiva, a cada formador o referencial de competências-chave da área de MV, nível B3, pedindo-se que selecionassem os critérios de evidência que consideravam obrigatórios para validação.

\section{RESUMOS}

Procurou-se através desta pesquisa aumentar o conhecimento acerca da atividade dos formadores numa tipologia formativa particular, o Reconhecimento e a Validação de Adquiridos. $O$ referencial de competências-chave emergiu enquanto principal instrumento da atividade destes formadores, mediando a sua ação em relação ao objeto, o reconhecimento e a validação dos saberes previamente adquiridos pelos formandos. Através da análise da atividade e de entrevistas coletivas a formadores, procurou-se conhecer, a natureza dos instrumentos mobilizados na atividade e o seu processo de atualização no uso. A análise dos dados demonstrou que os instrumentos evoluem através da atividade, traduzindo-se na sua contínua reconceção, através das géneses instrumentais. Compreendeu-se, ainda, que a larga margem de manobra concedida a estes formadores para fazerem evoluir os instrumentos é, em simultâneo, fonte de satisfação, pelo espaço que confere à inventividade do formador, mas também causa de desconforto, pela ausência de validação dessa evolução pelo coletivo de trabalho.

Se buscó, mediante esta investigación, aumentar el conocimiento sobre la actividad de los formadores en una tipología formativa particular, el reconocimiento y la validación de conocimientos adquiridos. El documento de referencia de competencias clave emergió como el principal instrumento de la actividad de estos formadores, mediando su acción con relación al objeto, al reconocimiento y a la validación de los saberes previamente adquiridos por las personas en formación. A través del análisis del trabajo y de entrevistas colectivas a formadores, se buscó conocer la naturaleza de los instrumentos movilizados en la actividad y su proceso de actualización en el uso. El análisis de los datos demostró que los instrumentos evolucionan a través de la actividad, lo que resulta en su continua reconfiguración, a través de las génesis instrumentales. Se comprendió, además, que el amplio margen de maniobra concedido a estos formadores, para que hagan evolucionar los instrumentos, es, a la vez, una fuente de satisfacción, ya que les abre un nuevo espacio para su inventiva, y causa de incomodidad, porque esa evolución no es validada por el grupo de trabajo.

Notre objectif, dans cette recherche était d'aboutir à une meilleure connaissance de l'activité des formateurs, dans le cadre d'un type de formation particulière : la reconnaissance et la validation des acquis. Le référentiel des compétences clé est apparu clairement comme étant l'instrument principal de l'activité de ces formateurs, médiateur de leur action par rapport à l'objet, à savoir, la reconnaissance et la validation des savoirs acquis au préalable par les formés. Partant de l'analyse du travail et d'entrevues collectives des formateurs, nous avons cherché à connaître la nature des instruments mobilisés dans l'activité et leur processus de mise à jour dans l'usage. L'analyse des données a démontré que les instruments évoluent à travers l'activité, ce qui se traduit par leur re-conception continuée, dans un processus de genèse instrumentale. Nous avons 
constaté, en outre, que la marge de manœuvre accordée à ces formateurs pour faire évoluer les instruments constitue une source de satisfaction, étant donné l'espace qu'elle confère à l'inventivité, tout en étant également source d'inconfort, en raison de l'absence de validation de cette évolution par le collectif de travail.

This research aimed at increasing the knowledge on the trainers' activity in a specific training typology, the Recognition and Validation of Prior Learning. The framework of key competences emerged as the main instrument for the development of these trainers' activity; it mediates their action towards the object, which is the recognition and the validation of knowledge previously acquired by the trainees. The work analysis and the group interviews to trainers were used to get to know the nature of the instruments that support the activity as well as their updating process while in use. The data analyses revealed that the instruments evolve alongside the activity, which means that they are continuously redesigned through the instrumental genesis. It was also understood that the broad leeway given to these trainers to contribute to the instruments' evolution causes them satisfaction, as the trainer is offered room for inventiveness but, simultaneously, it causes them discomfort, due to the lack of validation of such evolution by the work group.

\section{ÍNDICE}

Palabras claves: actividad de formador, instrumento, génesis instrumentales, reconocimiento y validación de conocimientos adquiridos

Keywords: trainer's activity, instrument, instrumental genesis, recognition and validation of prior learning

Palavras-chave: atividade de formador, instrumento, géneses instrumentais, reconhecimento e validação de adquiridos

Mots-clés: activité de formateur, instrument, genèses instrumentales, reconnaissance et validation des acquis

\section{AUTORES}

\section{JOANA FERNANDES}

Centro de Psicologia da Universidade do Porto, Faculdade de Psicologia e de Ciências da Educação da Universidade do Porto e Centro de Estudos em Desenvolvimento Humano, Faculdade de Educação e Psicologia, Universidade Católica Portuguesa, Rua Diogo Botelho, 1327, 4169-005 Porto jfernandes@porto.ucp.pt

\section{MARTA SANTOS}

Centro de Psicologia da Universidade do Porto, Faculdade de Psicologia e de Ciências da Educação da Universidade do Porto, Rua Alfredo Allen 4200-135 Porto

marta@fpce.up.pt 